\title{
PASTORAL DO POVO DE RUA: ESTRATÉGIAS E AÇÕES DE SOLIDARIEDADE
}

\section{Cássia Rozária da Silva Souza' \\ ORCID: 0000-0001-9790-3713}

Maria de Nazaré de Souza Ribeiro'

ORCID: 0000-0002-7641-1004

Camila Carlos Bezerra"

ORCID: 0000-0001-5896-5604

Cleisiane Xavier Diniz

ORCID: 0000-0003-4689-6204

Fernanda Farias de Castro' ORCID: 0000-0003-1970-5169

Josiani Nunes do Nascimento"' ORCID: 0000-0001-6841-9551

Vanusa do Nascimentoiv ORCID: 0000-0003-4141-2784

Universidade do Estado do Amazonas. Escola Superior de Ciências da Saúde. Manaus, Amazonas, Brasil.

"Universidade Federal do Amazonas. Manaus, Amazonas, Brasil.

I'Secretaria de Saúde do Estado do Amazonas-SUSAM. Manaus, Amazonas, Brasil.

IVFundação Universidade Aberta da Terceira Idade-FUnATI. Manaus, Amazonas, Brasil.

Autor Correspondente: Cássia Rozária da Silva Souza E-mail: crsouza@uea.edu.br

Como citar:

Souza CRS, Ribeiro MNS, Bezerra CC, Diniz CX, Castro FF, Castro JN, Nascimento V. Pastoral do povo de rua: estratégias e ações de solidariedade. In: Santana RF (Org.). Enfermagem gerontológica no cuidado do idoso em tempos da COVID 19.

Brasilia, DF: Editora ABen; 2021. 171 p.

(Serie Enfermagem e Pandemias, 5).

https://doi.org/10.51234/aben.21.e05.c12

\section{INTRODUÇÃO}

Durante a pandemia da COVID-19, enquanto as autoridades de saúde recomendavam o distanciamento social, uso de máscaras e a rigorosa higiene das mãos e do ambiente ${ }^{(1)}$, vários idosos que moram nas ruas tiveram e ainda tem que conviver com as incertezas do dia a dia, sobre o que comer, onde dormir, de onde receber ajuda visto que a circulação de pessoas que os ajudam diminuiu e os estabelecimentos comerciais foram fechados.

Nesse sentido questoes: Como manter um padrão de higiene requerido? Se antes tomar banho já era difícil para eles e, como distinguir os sintomas da COVID-19 de outros sintomas frequentes que já possuem e convivem há tanto tempo? Se para conter a doença e evitar a contaminação a proposta é ficar em casa, o que fazer aqueles que vivem nas ruas? Como pessoas idosas em situação de extrema vulnerabilidade social, coabitando com outras doenças podem se proteger da infecção? E o que fazer com essas pessoas que não tem casa? Se as condições de vida das pessoas idosas que vivem nas ruas já eram árduas, agora chamam a atenção de forma mais objetiva frente à pandemia.

Todavia, na omissão do Estado em assumir a responsabilidade da garantia de direitos prioritários e básicos a essa população, muitas dessas ações, de forma voluntária e solidária, estão sendo assumidas pela sociedade civil, constituídas pelo terceiro setor que agrega diversas entidades religiosas, associações e grupos filantrópicos conhecidos como Organizações Não Governamentais (ONGs). Elas são entidades sem fins lucrativos de apoio às pessoas mais vulneráveis, cuja finalidade é gerar serviços de ordem pública e benefício das mais variadas formas a quem precisar.

As ONGs atuam principalmente em locais, onde os serviços públicos se omitem, desenvolvem trabalhos na área da saúde, educação, assistência social e direitos humanos ${ }^{(2)}$. As ações acontecem no âmbito do voluntariado e solidariedade, na busca dos direitos e nas ações 
sociais que atenuam problemas emergenciais importantes. No caso dos moradores de rua, suas ações visam à construção ou reconstrução da identidade da pessoa, na superação das barreiras sociais, na expressão de sua cultura, atuando em diversos $\operatorname{campos}^{(2)}$. Uma das instituições mais atuantes nessa área hoje no Brasil é a Pastoral do Povo de Rua, da Igreja Católica(3).

Desde o início da pandemia da COVID-19 no Brasil, a Pastoral do Povo de Rua buscou alternativas para atender a população em situação de rua e criou redes de apoio e solidariedade mobilizando seus integrantes e implementando estratégias e ações exitosas de solidariedade, com respeito à heterogeneidade dessa população, principalmente da pessoa idosa que vive em situação de rua.

A postura da Pastoral do Povo de Rua foi sempre cobrar o comprometimento do poder público nas demandas relacionadas ao povo da rua para as questões de saúde, educação, habitação, trabalho/ocupação, segurança pública e demais carências existentes. Porém, na urgência do primeiro momento, diante da condição de descontrole epidemiológico da COVID-19, buscou possibilidades para, em conjunto, elaborar propostas de intervenção sobre a situação, que reduzissem o sofrimento dessas pessoas ${ }^{(3)}$.

Esse estudo visa refletir sobre as estratégias e ações de solidariedade realizadas pela Pastoral do Povo de Rua durante a pandemia da COVID-19 no Brasil e na cidade de Manaus-Amazonas, a primeira capital brasileira a apresentar colapso dos serviços de saúde no período do epicentro da doença no país. O estudo serve também de reflexão sobre os processos sociais geradores das condições que se fazem presentes na vida de pessoas idosas em situação de rua e o importante papel da sociedade civil em ações de solidariedade.

\section{OBJETIVO}

Refletir sobre as estratégias e ações de solidariedade realizadas pela Pastoral do Povo de Rua durante a pandemia da COVID-19 no Brasil e na cidade de Manaus-Amazonas, pontuando a importância das ações do terceiro setor e a necessidade de ações governamentais efetivas para a garantia de direitos e resgate da dignidade dessas pessoas.

\section{MÉTODO}

Trata-se de estudo teórico-reflexivo sobre as estratégias e ações de solidariedade implementadas pela Pastoral do Povo de Rua para atender idosos em situações de ruas durante a pandemia da COVID-19 no Brasil e na cidade de Manaus-Amazonas. As reflexões foram embasadas em artigos científicos relacionados ao tema, bem como nas experiências das autoras. Assim, as considerações foram categorizadas em três pilares: 1) A Pastoral do Povo de Rua; 2) A pessoa idosa em situação de rua e a pandemia da COVID-19; 3) Estratégias e Ações de solidariedade da Pastoral do Povo de Rua ao idoso frente à pandemia. A Resolução No466/2012-CN/ MS não se aplica neste estudo, por se tratar de uma investigação de reflexão teórica.

\section{RESULTADOS}

\section{A Pastoral do Povo De Rua}

Na maioria das grandes cidades brasileiras, o cenário das ruas mostra um povo que luta para sobreviver. São crianças, jovens, adultos e idosos, vivendo debaixo de marquises e viadutos ou em casas desocupadas, trabalham puxando pesados carrinhos pelas ruas, becos e lixões da cidade, coletando materiais reutilizáveis para vender, sofrendo todo tipo de estigma da exclusão social.

É no meio desse cenário de desigualdade, pobreza e vulnerabilidade de muitas pessoas em situação de rua, que a Pastoral do Povo de Rua assume como missão ser presença na vida delas, ajudando a reconhecer os sinais de Deus presentes em sua história;a desenvolver ações que transformem a dura realidade da 
população em situação de rua e, estimular ações que ajudem a construir novas possibilidades em defesa da vida e na elaboração e desenvolvimento de políticas públicas concretas que atendam suas necessidades.

A Pastoral do Povo da Rua é uma ação da Igreja católica junto às pessoas mais sofredoras que moram que vivem nas ruas das cidades em situação de pobreza, miséria, marginalização e exclusão. Essas situações, muitas vezes, são tão perversas e cruéis que desumanizam as pessoas: negando-lhes condições básicas de sobrevivência, excluindo-as da convivência na sociedade ou marginalizando-as, a tal nível que se sintam abandonadas por Deus ${ }^{(4)}$.

A sede da Pastoral do Povo de Rua Nacional encontra-se em Belo Horizonte, Minas Gerais e existem Pastorais do Povo de Rua em diferentes cidades brasileiras, que foram implantadas em anos diferentes de acordo com o interesse e fortalecimento das pessoas que decidiram atuar frente a essa demanda. Nos primórdios da década de 1970, a Pastoral do Povo da Rua, da Igreja Católica, começou a organizar e instituir casas de acolhidas para as pessoas em situação de rua, estimulando a organização de movimentos populares de pessoas vivendo em situação de rua e catadores de materiais recicláveis, bem como a realização de eventos sociais nas cidades de São Paulo e Belo Horizonte ${ }^{(4)}$.

Desde o ano de 2001 faz parte da Comissão Episcopal Pastoral para o Serviço da Caridade, da Justiça e da Paz da Conferência dos Bispos do Brasil (CNBB). Em Manaus, foi implantada oficialmente no ano de 2015, mas já realizava ações concretas junto ao povo em situação de rua ${ }^{(3-4)}$.

Devido às condições sub-humanas em que vivem as pessoas em situação de rua, a Pastoral do Povo de Rua acredita que o estabelecimento de relações fraternas e humanas é de fundamental importância para a afirmação da dignidade, a recuperação da autoestima, a redescoberta e reafirmação do amor de Deus para com essas pessoas, além da abertura de novos horizontes e perspectivas de futuro. Dessa forma, defender e cuidar da vida são sinais humanos eficazes e mobilizadores que provocam mudanças, abrem possibilidades de vida e desencadeiam expectativas de novos processos ${ }^{(3)}$.

A experiência da Pastoral do Povo da Rua tem mostrado que os processos mais férteis e dinâmicos de organização e conquista de direitos começam pelas pequenas ações de humanização da vida e das relações com e entre as pessoas em situação de rua. Dessa forma, tenta dar resposta a essa questão em duas das suas atuais diretrizes: a elaboração e implementação de políticas públicas e o controle social.

As políticas públicas têm a função de reduzir o abismo existente entre aqueles que vivem cercados de privilégios e os que nada têm. Esse abismo é consequência do modelo econômico vigente no país e na maior parte do mundo, que gera pobreza e aumenta as desigualdades sociais, sendo responsável pela intensificação e aumento do fenômeno população em situação de rua nas cidades.

Assim, as políticas públicas tornam-se importantes porque oferecem instrumentos para que os pobres tenham possibilidade de acesso aos bens e serviços produzidos socialmente ${ }^{(5)}$. Das diretrizes da Pastoral do Povo de Rua, a luta por políticas públicas é a mais difícil por exigir articulações tensas e trabalhosas com setores públicos. Todavia é uma efetiva via de transformação social ${ }^{(3)}$.

Para conquistar políticas públicas estruturantes, que incidam e criem raízes na política social, é fundamental a incidência em espaços de controle social. Essa diretriz da Pastoral do Povo de Rua se efetiva por meio da participação popular, com a organização do povo da rua e vivência comunitária. Nesse exercício a Pastoral do Povo de Rua é protagonista. Além de estimular e potencializar a participação do povo da rua em espaços decisórios, ela investe na formação constante dos agentes (voluntários), na ampliação do debate com parceiros e na busca pela produção do conhecimento ${ }^{(4,6)}$.

\section{Pessoas idosas em situação de rua e a pandemia da COVID-19}

Envelhecer num país latino-americano, envolto a um contexto onde se registram profundas desigualdades sociais, tem se tornado um grande desafio para muitas pessoas idosas. O mais importante não é o prolongamento da vida, mas viver com dignidade e esse tema têm sido pautado constantemente nas agendas 
governamentais dos países latino-americanos nas últimas décadas do século 21 . No entanto, observando a situação social dos países da América latina, destacando o Brasil, a partir de uma ótica de direitos, constata-se que, entre as prerrogativas legais já conquistadas e a real efetivação de direitos na vida da população idosa, há um longo distanciamento.

As desigualdades sociais que levam às situações de vulnerabilidade de muitas pessoas idosas são realidades prementes no Brasil, somadas a outras carências como as de saúde, assistência social e bons vínculos familiares. Tais realidades expulsam para as ruas todos os anos milhares de pessoas que acabam passando pelo processo de envelhecimento no ambiente de rua ou para lá são conduzidos em plena velhice por diferentes circunstâncias.

O Brasil não possui dados oficiais sobre a população em situação de rua, o que ajuda a tornar invisível essa problemática. Em 2015, o Instituto de Pesquisa Econômica Aplicada (IPEA) projetou para o Brasil 101.854 pessoas vivendo em situação de rua, estando 40,1\% em cidades com mais de 900 mil habitantes e 77,02\% em cidades com mais de 100 mil habitantes, ou seja, o maior número de pessoas está nas grandes metrópoles. Em 2016, 60.816 homens e mulheres com 60 anos ou mais, que estavam vivendo em situação de rua, procuraram albergues públicos para abrigarem-se ${ }^{(7)}$.

Dentre as circunstâncias que levam as pessoas à situação de rua, as mais comuns são: os conflitos familiares, a violência, o desamparo, as doenças, os vícios e a perda de atividade laboral. Estando na rua, sobrevivem de mendicância e trabalhos diversificados, precários e às vezes, subumanos. Assim, o prolongamento da vida nas ruas em condições desfavoráveis, expõe a pessoa a um processo progressivo e rápido de perdas da autoestima, da independência, da saúde mental, da qualidade de vida e de sua dignidade, vivendo na dependência de instituições assistenciais para realizar minimamente suas principais necessidades humanas básicas: alimentação, higiene, sono/repouso ${ }^{(8)}$.

Morar nas ruas ou estar nas ruas durante a velhice implica em maior exposição à violência e a criminalidade, às doenças e sua cronificação, a dificuldade de acesso aos serviços de saúde e sociais, refletindo na baixa expectativa de vida. Segundo estudos realizados com pessoas em situação de rua, as de idade superior a 50 anos possuem a pior condição de saúde, além de representar a maior taxa de consumo de drogas, porém, com maior acesso aos serviços de assistência social(9). Dentre estes, está um considerável número de idosos que envelheceram nas ruas ou foram para as ruas após alcançarem a idade cronológica de 60 anos.

O idoso possui uma imunidade sabidamente frágil, seja pelo processo de envelhecimento, pela presença de doenças, em virtude das particularidades de seu viver e das condições a que são expostos diariamente na rua. $\mathrm{O}$ acesso às mínimas condições de higiene, boa alimentação, sono e repouso e outras necessidades básicas, dificulta as chances de inclusão e consequentemente a melhoria das condições de vida e saúde ${ }^{(5)}$.

Existem muitos outros problemas que são exclusivos das pessoas que vivem em situação de rua e, dentre eles, os idosos carregam um adicional por já manifestarem prejuízo na saúde física e mental pelo avançar da idade, por altas taxas de doenças crônicas ou sistema imunológico comprometido, fatores de risco para o desenvolvimento de uma manifestação mais séria da infecção por coronavírus ${ }^{(2)}$. No risco iminente do contágio pelo novo coronavírus, é preciso ir além das políticas globais, investindo em controle nos abrigos, incluindo a testagem dessas pessoas e funcionários, isolamento imediato dos sintomáticos, tratamento aos doentes e todas as medidas de prevenção possíveis.

Ressalta-se que o idoso em situação de rua traz consigo fortes influências sociais que contribui para uma imagem estigmatizante, taxado como vagabundo, inútil ou criminoso. Contudo, o cotidiano dessas pessoas é cheio de intensa atividade laboral, tornando-os ativos na tentativa de se reinventarem como pessoas e resistirem às práticas de exclusão da sociedade e às dificuldades habituais ${ }^{(10)}$.

\section{Estratégias e ações de solidariedade da pastoral do povo de rua ao idoso frente a pandemia}

Dentre as ações que as Pastorais do povo de Rua realizaram nesse período de pandemia, estão: 
1. efetivar parcerias e aproximação com a rede de saúde locais, permitindo que o morador de rua pudesse ter acesso aos serviços de saúde de forma mais efetiva;

2. acompanhar o processo de abrigamento que os órgãos governamentais teriam que assumir frente a essas pessoas, pois sem essa cobrança, muitos desses abrigos não teriam se efetivado ou ainda, estariam funcionando de forma inexpressiva frente às necessidades da população de rua;

3. executar estratégias de aproximação e cobrança junto a defensoria e ministério público, visando exigir a efetivação do papel do Estado;

4. fortalecer a participação e controle social dos moradores de rua, incentivando que os mesmos sejam protagonistas de seus direitos;

5. realizar ações de saúde com acompanhamento individual e em campanhas coletivas de atendimento;

6. arrecadar e distribuir roupas, material de higiene pessoal e de limpeza e cestas básicas para os moradores de ruas, pessoas em vulnerabilidade social e casas de apoio que oferecem serviços de atendimento e alimentação;

7. preparar e distribuir refeições as pessoas em situação de rua em dias e horários que possam minimizar a situação de fome que essas pessoas estão expostas;

8. manter diálogos tanto com os moradores de rua como com os gestores que deliberam sobre as ações de prevenção do coronavírus, no intuito da inserção igualitária das ações de controle, prevenção e tratamento da COVID-19 a essas pessoas também;

9. solicitar a realização de testagem para COVID-19 nos casos suspeitos e, por ocasião do abrigamento, a oferta de outros serviços de saúde, como a consulta médica, disponibilidade e liberação de medicamentos para início do tratamento de doenças identificadas, entre eles, tuberculose e HIV;

10. ofertar em parceria, acesso a serviços jurídicos para retirada de documentos e cadastro no Cadúnico, que na formatação que se encontra, não favorece a inclusão dos moradores de rua nos serviços que são associados a esse cadastro entre outras ações e;

11. encaminhar aos parceiros possibilidades de formação educacional, de capacitação e vínculo empregatício dentro das possibilidades demandadas pela Pastoral do Povo de Rua.

A exemplo de Manaus, as Pastorais do Povo de Rua de outras cidades, foram extremamente importantes para que estratégias e ações de atendimento a essas pessoas pudessem acontecer, acionando o poder público que interveio junto ao Estado que apesar de anunciar o abrigamento, deixou por dias os moradores no lado de fora do prédio que estava destinado a esse fim, precisando também supervisionar a oferta de uma alimentação adequada e condições de atendimento interno, como a oferta de banho diário, troca de roupa limpas e material de higiene.

A Pastoral segue atuando para que o abrigamento não seja simplesmente desfeito, mas que se possam direcionar essas pessoas para locais adequados, inclusive clínicas de recuperação que o poder público tem gerenciamento ou convênio, retorno ao meio familiar, etc., com o acompanhamento psicológico, de serviço social e da própria igreja, enquanto fortalecimento da crença em dias melhores diante da fé e com atitudes positivas.

\section{Limitações do estudo}

A ausência de dados oficiais sobre a população de rua, inclusive sobre os idosos que vivem nessa situação por parte dos órgãos governamentais e de gerencia sobre essa área e, a não publicação das ações da Pastoral do Povo de Rua, que descrevem todas as atividades e parcerias que realizam para a concretude das intervenções, bem como a falta de pesquisas pertinentes às pessoas idosas em situação de rua, foram os maiores limitadores para a construção deste estudo. 


\section{Contribuição para a enfermagem}

O estudo permite à enfermagem uma reflexão sobre as pessoas idosas em situação de rua e suas necessidades, podendo, o profissional, apoiar as estratégias e ações de solidariedade individual ou coletiva proporcionadas pela Pastoral do Povo de Rua ou outras ONGs que atuam junto a eles. A partir desta reflexão, a enfermagem também deve se sentir convocada a participar das lutas para a conquista social, política e de saúde das pessoas em situação de rua, atuando diretamente, propondo ações e contribuindo na implementação das políticas e ações junto a este segmento, podendo servir como um dos alicerces para a reconstrução políticas públicas de parceria e intervenção junto ao idoso em situação de rua.

\section{CONSIDERAÇÕES FINAIS}

Uma característica que ainda é bem marcante nesse segmento é o assistencialismo das ações. Promover a reintegração das pessoas idosas em situação de rua em seu meio familiar ou ao menos, ao seu meio social, garantindo-lhe independência social, resgatando seus valores humanos, dando a oportunidade de melhorar sua qualidade de vida e readquirindo sua dignidade pessoal. Por meio da abordagem social, o Poder Público tem o dever de promover a reinserção da pessoa idosa na rede de serviços sócio-assistenciais, por exemplo, o Cadastro Único, possibilita que ele tenha acesso a alguns serviços primordiais de ajuda. A pandemia da COVID-19 vem de encontro à necessidade de traçar estratégias urgentes e pontuais quanto a assistência e cuidados as pessoas idosas em situação de rua no Brasil. A Pastoral do Povo de Rua apresenta-se como instrumento de mediação para favorecer o empoderamento do indivíduo e acompanhar, assim como cobrar que o poder público se apresente dentro de seu papel de gestor. A enfermagem como agente natural de sua formação pode participar ativamente não apenas no cuidado a esses menos favorecidos, mas também desenvolvendo suas ações na área de educação em saúde, fortalecendo ainda mais essa transformação de cenários e direitos.

\section{AGRADECIMENTO}

Ao Departamento Científico de Enfermagem Gerontológica da ABEn Nacional.

\section{REFERÊNCIAS}

12. Pinto RMP, Gondim ABC. Trabalho e População em Situação de Rua: uma análise à luz da questão social [Internet]. VII Jornada Internacional de Políticas Públicas, São Luis, Ago, 2017[cited 2020 Jul 03]. Available from: https://www.joinpp. ufma.br/jornadas/joinpp2017/pdfs/eixo1/trabalhoepopulacaoemsituacao deruaumaanalisealuzdaquestaosocial.pdf

13. Tsai J, Wilson M. COVID-19: um potencial problema de saúde pública para populações de rua. Lancet Public Health. 2020;5(4):e186-e187. https://doi.org/10.1016/S2468-2667(20)30053-0

14. Conferência Nacional dos Bispos do Brasil. Pastoral do Povo da Rua. Brasília (DF): CNBB[Internet]. 2020 [cited 2020 Jul 03]. Available from: https://www.cnbb.org.br/pastoral-do-povo-da-rua/

15. Roletti MCB. Pastoral Nacional do Povo da Rua: uma pastoral urbana a serviço da vida. Migranteshoy [Internet]. 2015[cited 2020 Jul 03]. Available from: http://migranteshoy.celam.org/inicio-brasil.html

16. Hino P, Santos JO, Rosa AS. People living on the street from the health point of view. Rev Bras Enferm. 2018;71(supl.1):68492. https://doi.org/10.1590/0034-7167-2017-0547

17. Lima NNR, Souza RI, Feitosa PWG, Moreira JLS, Silva CGL, Rolim Neto ML. Pessoas em situação de rua: sua potencial exposição ao COVID-19. Psiquiatr Res. 2020;288:112945. https://doi.org/10.1016/j.psychres.2020.112945

18. Instituto de Pesquisa Econômica Aplicada (IPEA). Estimativa da população em situação de rua no Brasil: texto para discussão [Internet]. 2016[cited 2020 Jul 03]. Available from: http://repositorio.ipea.gov.br/bitstream/11058/7289/1/ td_2246.pdf 
19. Bove C, Figueiredo G. População em situação de rua [Internet]. Brasília: Secretaria de Direitos Humanos da Presidência da República; 2015[cited 2020 Jul 03]. Coleção Caravana de Educação em Direitos Humanos. Available from: http://flacso.org. br/files/2017/06/popula\%c3\%87ao-em-situa\%c3\%87\%c3\%83o-de-rua.pdf.

20. Freire-Neto JB. Carta aberta à população brasileira [Internet]. Rio de Janeiro: Sociedade Brasileira de Geriatria e Gerontologia; 2014[cited 2020 Jul 03]. Available from: http://itarget.com.br/newclients/sbgg.com.br/wp-content/ uploads/2014/10/carta-aberta-aos-brasileiros.pdf

21. Monteiro-Jr RS, Carneiro LSF, Barca ML, Kristiansen KM, Sampaio CS, Haikal DS, et al. COVID-19 Pandemic: a multinational report providing professional experiences in the management of mental health of elderly. Int Psychogeriatr. 2020;1-4. https://doi.org/10.1017/S1041610220001027 